\title{
Different paths from transparency to trust? A comparative analysis of Finnish and Italian listed companies' investor relations communication practices
}

\author{
Merja Koskela*, University of Vaasa, Department of Communication Studies, Finland \\ Belinda Crawford Camiciottoli, University of Pisa, Department of Philology, Literature \\ and Linguistics, Italy \\ *Corresponding author: mko@uwasa.fi
}

\begin{abstract}
This paper investigates how companies seek to convey an image of transparency in their investor relations (IR) communication policy texts. It is based on two corpora compiled from texts describing the IR communication policies of companies listed on the Finnish OMX Helsinki 25 and the Italian FTSE MIB 40, representing two culturally different players within the European financial community. A two-pronged methodology was used to identify the linguistic and discursive expression of the concept of transparency: corpus-driven micro-linguistic analysis and rhetorical move analysis. Results showed that transparency and dialogue were keywords only in the Italian corpus. They further suggested that Finnish companies focus more on the efficient disclosure of information, whereas the Italian companies highlight their commitment to constant dialogue with stakeholders. The findings can be interpreted as reflecting cultural differences between the countries in terms of contextual vs. personal, affective vs. instrumental, and elaborate vs. exacting communication styles.
\end{abstract}

\section{Keywords}

investor relations, communication policy, transparency, trust, corpus methodology, rhetorical move analysis, cultural differences

\section{Introduction}

In corporate settings, the area of investor relations (IR) constitutes a vital component of strategic communication. According to Marston (1996, p. 447), IR can be described as "the link between a company and the financial community, providing information to help the financial community and investing public evaluate a company". Consequently, one of the most important functions of IR is financial disclosure (i.e., the public release of financial information), which is crucial for the successful management of stakeholder support (Argenti, 2009). However, effective IR is concerned not only with the disclosure of information, but also with the quality of communication, which in the context of IR should be perceived as "competent, transparent and reliable" (Hoffman \& Fieseler, 2012, p. 146), so that investors can acquire understanding and trust in relation to the company and its financial situation.

The language that companies use to convey an image of transparency is likely affected by cultural considerations, attitudes, and values (see e.g. Amernic, Craig, \& Tourish, 2010; Craig \& Brennan, 2012; Leibbrand, 2015; Koskela, 2018). Accordingly, Volk (2017) makes a strong case for implementing a comparative approach when studying communication in a global context by stating that strategic communication is clearly adapted to cultural conditions across countries. Therefore, cross-cultural comparisons open new avenues for an analysis of how the changing global environment and diverse cultural settings are reflected in the linguistic and rhetorical features of IR communication.

Even though today's business world is globalized, differences in company communication practices across countries 
persist (Melgin, Luoma-aho, Hara, \& Melgin, 2018). In other words, the business context tends to shape the discourse that is used. Whether or not, and to which degree, such differences may be attributed to aspects of culture remains to be debated, depending on the way culture is defined. For example, culture may be construed as encompassing the prevailing traditions and values associated with the national context, but also as the regulatory frameworks within which the company in question operates.

This research focuses on texts that companies produce to articulate their IR communication policy (hereafter IR policy). These are strategic texts that outline how companies intend to communicate with their stakeholders in order to achieve their goals (Koskela, 2018). Unlike other communication strategy texts, IR policies are public as they are typically located on the IR websites of listed companies; they are dedicated to explaining to stakeholders which communication principles a company follows in its IR communication, such as quality requirements for information and the channels used. In the European context, this practice stems from the guidelines stated by the European Union in its Transparency Directive from 2004 (2004/109/EC; 2013/50/EU), which aims to guarantee a regular flow of financial information to the market. Publishing an IR policy is a way for companies to demonstrate transparency to the financial markets and to convince their stakeholders that they can be trusted as investment objects.

In this paper, we aim to gain insights into how transparency is conceptualized in IR communication practices of Finnish and Italian listed companies. We focus on one particular transparency practice, namely published IR policies and explore the potential influence of national cultures on the understanding of what constitutes transparency and how it may lead to trust. In particular, we address the following research questions:

1. Which linguistic and discursive features are used to convey transparency in the IR policies of Finnish vs. Italian listed companies?

2. What are the similarities and differences in their IR policies?

3. What role do cultural values play when communicating transparency?

In the following section, we delve deeper into the concept of transparency as the underlying construct of the present study.

\section{Understanding and implementing transparency}

Transparency is a complex concept with various interpretations in different contexts (Christensen \& Cheney, 2015). In its basic form, in business settings transparency has been equated with financial disclosure, reporting, or simply any type of information-giving. As such, it bears connotations of honesty and good governance, in particular when it comes to stakeholder demands and requirements of authorities in cases of ethical or moral misbehavior.

According to Rawlins (2009), transparency refers to the deliberate attempt by companies to release all positive and negative information that is legally releasable in an accurate, timely, balanced, and unequivocal manner in order to enable the public to hold the company accountable for its actions. Furthermore, Rawlins makes a distinction between two quantitatively measurable types of transparency, namely organizational transparency and communicative transparency. While organizational transparency has to do with the organization's reputation as a transparent actor, communicative transparency refers to the communicative efforts that the organization engages in to be perceived as transparent. This distinction is relevant for our study because IR policy combines both types: it can be said that IR policies strive to create organizational transparency by means of communicative transparency.

To effectively respond to an increasing demand for transparency (e.g. Baraibar-Diez, Odriozola, \& Fernández Sánchez, 
2016), companies need to decide how they want to display their transparency, that is, which communicative measures are needed to convince their publics of their organizational transparency. To achieve this, information-giving is not enough; active participation of stakeholders and other publics is also required. Moreover, true transparency means that the messages communicated by the company are both understandable and relevant to the public (Albu \& Wehmeier, 2014). However, Lee and Boynton (2017) point out that transparency is not just for the benefit of the stakeholder because companies can use it to prevent problems from arising. Furthermore, companies have come to realize that transparency requirements may bring about reputational risks because they inevitably remind stakeholders of the downside of transparency, that is, concealment, corruption, and mistrust (Hansen, Christensen, \& Flyverbom, 2015).

One way of accomplishing communicative transparency is the publication of the company's underlying principles for communicating with their stakeholders on its IR website. These principles may take different forms, among which is a disclosure policy (see Koskela, 2018; Koskela \& Kuronen, 2014). Guimard (2008) states that publishing a disclosure policy has become an established best practice in the United States. This is evident from the website of the U.S. National Investor Relations Institute (NIRI, 2018), which describes the disclosure policy as a voluntary document "designed to reflect current best practices in corporate disclosure". The NIRI provides guidelines on how to write a disclosure policy. In terms of content, such policies typically contain recommendations for employees when communicating with media and other outsiders, rules for what and when the company publishes according to which disclosure principles, frequency of publishing, as well as information about when the company is not communicating with the markets (quiet period) (Guimard, 2008, pp. 150-151). The table of contents of the American company Xerox provides a good example of this type of content. Specifically, it includes an overview of the type of information to be disclosed (as well as information not be disclosed and unintentional disclosure), authorized spokespersons, intended audiences, timing of disclosure, and company quiet periods (Xerox, 2008).

In Europe, however, publishing a short IR policy statement, rather than a full-scale disclosure policy, seems to be more common. Policy statements with rather standardized content and structure are not always perceived as efficient because they may only resort to delivering an image of openness to publics outside, while company-internal forces may resist the practice altogether (Hansen et al., 2015, p. 120). Yet these statements nonetheless serve a purpose in the construction of transparency. This is because, as a practice shared by several companies in reproducing and communicating a similar ideal, it may counteract the potential negative interpretations and consequences of transparency communication (see Hansen et al., 2015; Koskela, 2018). In addition, the frequent use of such statements creates expectations among the users of corporate websites, which again affect the ways companies choose to develop their IR policy.

As a combination of its organizational and communicative forms, transparency in the financial markets has become a discursive and rhetorical concept created and developed in the IR practices of companies. These practices are shaped by institutional regulations and guidance, business cultures, and company specific factors. In the current paper, we focus on national differences between Finland and Italy, representing two distinctive poles in the European context, both geographically and culturally. The institutional regulations behind the transparency practices are shared at the level of European directives, but differ in their implementation by the stock exchanges of the two countries as illustrated in Table 1. The table reproduces key extracts of published normative documents and guidelines in relation to IR policy, starting from the overarching EU directive, and followed by extracts from the Finnish and Italian normative documentation where the non-mandatory nature 
Table 1: The normative background for IR policy documents

\begin{tabular}{|c|c|c|}
\hline EU & Finland & Italy \\
\hline $\begin{array}{l}\text { [...] The disclosure of accurate, comprehen- } \\
\text { sive and timely information about security } \\
\text { issuers builds sustained investor confidence } \\
\text { and allows an informed assessment of } \\
\text { their business performance and assets. } \\
\text { This enhances both investor protection and } \\
\text { market efficiency. }\end{array}$ & $\begin{array}{l}\text { To ensure that the company provides the } \\
\text { market with timely, reliable, accurate and } \\
\text { up-to-date information, the exchange encour- } \\
\text { ages the company to adopt an information } \\
\text { and disclosure policy. A company's informa- } \\
\text { tion and disclosure policy is a document that } \\
\text { helps the company to continuously provide } \\
\text { high-quality internal and external informa- } \\
\text { tion. It should be formulated in such } \\
\text { a manner that compliance with it is not } \\
\text { dependent on a single person, and it should } \\
\text { also be designed to fit the circumstances } \\
\text { pertaining to the specific company. }\end{array}$ & $\begin{array}{l}\text { Although it is to be hoped that issuers } \\
\text { will adopt a policy aimed at implementing } \\
\text { procedures for meeting with the financial } \\
\text { community that conform as much as possible } \\
\text { to the "open-door" principle [...] } \\
\text { It is to be hoped that issuers will put in place } \\
\text { a policy for disclosing forward-looking infor- } \\
\text { mation to the market, as also recommended } \\
\text { by Consob. As things stand, however, it has } \\
\text { been thought preferable to leave it to them } \\
\text { to evaluate the desirability of following such } \\
\text { a course. }\end{array}$ \\
\hline
\end{tabular}

Note: The data in the table were retrieved from various sources. The EU legislation data stems from the Directive 2004/109/EC. The Finnish norms were gathered from the Rules of the exchange (see Nasdaq Nordic, 2019 for the latest version). Reference to the Italian normative background was extracted from the Guide to the disclosure of information to the market (Borsa Italiana, 2002).

of such policy clearly emerges through the linguistic items highlighted in italics.

The voluntary nature, as well as the variability in the labelling, content, and format of texts designed to communicate IR policy, may help explain why, unlike other financial genres, IR policy has not yet attained a distinctive generic status. Interestingly, neither disclosure policy nor IR policy is listed by Palmieri (2018) in the genre system of financial communication, which includes a wide range of different spoken and written genres used by companies, investors, and financial intermediaries (e.g., annual/ quarterly reports, earnings conference calls, earnings releases, analyst's reports). Earlier research has naturally concentrated on the genres with established genre labels, such as annual reports (e.g. Laskin, 2018), letters to shareholders (e.g. Poole, 2016), earnings conference calls (Crawford Camiciottoli, 2018), and fund manager commentaries (Bruce, 2014).

Transparency is seen as prerequisite for trust, which is the underlying reason for the rules and recommendations illustrated in Table 1. In corporate settings, trust is also a complex concept involving the belief that a company will act in the stakeholders' best interest, further their interests, and intentionally cause no harm (Rousseau, Sitkin, Burt, \& Camerer, 1998). ${ }^{1}$

1 For an in-depth discussion of trust in the context of financial markets, see Laskin (2018) and Strauss (2018).
(Re)creating trust among stakeholders is the ultimate goal of IR. In IR communication, openness and transparency form a path towards trust, when information giving is supported by continuous and direct contacts with stakeholders (see e.g. Strauss, 2018). Publishing a policy document that explains to stakeholders which principles the company follows in its IR communication is a means to build trust through transparency. Consequently, companies may pursue trust through transparency by not only adopting some type of IR policy (organizational transparency), but also by making it public (communicative transparency), although this is not explicitly required in the rules and regulations, as shown in Table 1.

\section{Data and methods}

The analysis was based on two ad-hoc corpora compiled from textual data relating to IR policy available on the English versions of the websites of companies listed on the Finnish and Italian benchmark stock indices: OMX Helsinki 25 and FTSE MIB 40. We carefully examined the IR website of each listed company to identify any information pertaining to IR policy. In some cases, this information was accessible directly from the IR web page, through hypertext links distinctly labelled "IR Policy" or similar. In other cases, such information was instead embedded within other types of 
Table 2: The Italian corpus

\begin{tabular}{|c|c|c|}
\hline Company & Business Sector & Word Count \\
\hline$\overline{A 2 A}$ & Electricity & 535 \\
\hline Ansaldo STS & Industrial Transportation & 956 \\
\hline Atlantia & Industrial Transportation & 241 \\
\hline Autogrill & Travel \& Leisure & 858 \\
\hline Azimut Holding & Financial Services & 88 \\
\hline Banca Monte dei Paschi di Siena & Banks & 749 \\
\hline Banca Popolare dell'Emilia Romagna & Banks & 299 \\
\hline Banca Popolare di Milano & Banks & 672 \\
\hline Banco Popolare & Banks & 244 \\
\hline Buzzi Unicem & Construction \& Materials & 922 \\
\hline Campari & Beverages & 611 \\
\hline CNH Industrial & Trucks / construction machinery & 224 \\
\hline Enel & Electricity & 262 \\
\hline Enel Green Power & Electricity & 675 \\
\hline Eni & Oil \& Gas Producers & 175 \\
\hline Exor & Financial Services & 79 \\
\hline Fiat & Automobiles \& Parts & 174 \\
\hline Finmeccanica & Aerospace \& Defense & 379 \\
\hline Generali & Nonlife Insurance & 271 \\
\hline GTECH & Travel \& Leisure & 196 \\
\hline Intesa Sanpaolo & Banks & 794 \\
\hline Luxottica & Personal Goods & 226 \\
\hline Mediaset & Media & 298 \\
\hline Mediobanca & Banks & 192 \\
\hline Mediolanum & Life Insurance / Assurance & 249 \\
\hline Pirelli \& C. & Automobiles \& Parts & 315 \\
\hline Prysmian & Electronic \& Electrical Equipment & 332 \\
\hline Saipem & Oil Equipment Services / Distribution & 647 \\
\hline Salvatore Ferragamo & Personal Goods & 858 \\
\hline Snam & Gas, Water \& Multiutilities & 1087 \\
\hline STMicroelectronics & Technology, Hardware \& Equipment & 621 \\
\hline Telecom Italia & Fixed Line Telecommunications & 742 \\
\hline Tenaris & Industrial Metals \& Mining & 0 \\
\hline Terna & Electricity & 317 \\
\hline Tod's & Personal Goods & 243 \\
\hline UBI Banca & Banks & 1065 \\
\hline UniCredit & Banks & 267 \\
\hline UnipolSai & Nonlife Insurance & 148 \\
\hline World Duty Free & Retail & 1149 \\
\hline \multirow[t]{2}{*}{ YOOX } & Personal Goods & 319 \\
\hline & & 18479 \\
\hline
\end{tabular}

documentation available on the IR website, including the corporate governance report, the annual report, and the code of ethics / conduct. To identify any relevant parts of these texts where IR policy might be addressed, we performed searches ba- sed on the items investor relations, policy, communication, and disclosure.

Among the 40 Italian companies, all but one (Tenaris) provided at least some information pertaining to IR policy. However, only 10 out of 40 companies (25\%) 
Table 3: The Finnish corpus

\begin{tabular}{|c|c|c|}
\hline Company & Business Sector & Word Count \\
\hline Amer Sports & Personal \& Household goods & 239 \\
\hline Cargotec & Industrial Machinery & 1599 \\
\hline Elisa & Integrated Telecommunication Services & 1260 \\
\hline Fortum & Electric Utilities & 2102 \\
\hline Huhtamäki & Industrial Goods \& Services & 2069 \\
\hline Kemira & Diversified Chemicals & 108 \\
\hline Kesko & Food Retail & 230 \\
\hline Kone & Industrial Machinery & 133 \\
\hline Konecranes & Industrial Machinery & 132 \\
\hline Metso & Industrial Machinery & 2270 \\
\hline Neste & Oil and Gas Refining and Marketing & 3043 \\
\hline Nokia & Communications Equipment & 0 \\
\hline Nokian Tyres & Tyres and Rubber & 141 \\
\hline Nordea Bank & Diversified Banks & 22 \\
\hline Orion & Pharmaceuticals & 819 \\
\hline Outokumpu & Steel & 1623 \\
\hline Outotec & Construction and Engineering & 1384 \\
\hline Sampo & Multi-line Insurance & 1804 \\
\hline Stora Enso R & Paper Products & 2355 \\
\hline Telia & Integrated Telecommunication Services & 755 \\
\hline Tieto & Technology (IT) Services & 420 \\
\hline UPM-Kymmene & Paper Products & 957 \\
\hline Valmet & Industrial Goods \& Services & 2073 \\
\hline Wärtsilä & Industrial Machinery & 2588 \\
\hline YIT & Construction and Engineering & 1590 \\
\hline
\end{tabular}

had a direct link to an "IR Policy", typically a short text of 100 words or less. For the remaining companies, the relative information was located across the other types of financial documentation as indicated. Interestingly, none of the Italian companies provided a document similar to the relatively lengthy and well-articulated disclosure policy of Xerox (2008) as mentioned previously.

Among the Finnish companies, on the contrary, 22 of 25 of the companies (88\%) had some type of policy, either documents labelled Disclosure Policy (16) and / or an IR policy (12), and / or a related web text (7). The "IR policies" were located either as an introduction to a Disclosure Policy (8 companies) or as a separate policy (4 companies). Because of the strong presence of disclosure policies, comparable or the same information was sought in other documents, such as annual reports, only when no type of specific policy was found. This was the case for three companies, i. e., Kemira, Nokia, and Nordea, out of which only one (Nokia) turned out to have no relevant information.

All textual material identified as relevant to IR policy was then compiled into two comparable corpora: the Italian IR policy corpus and the Finnish IR policy corpus (hereafter the Italian corpus and the Finnish corpus). Tables 2 and 3 provide overviews of the two corpora which were collected over a one-year period from November 2016 to November 2017. The word counts refer to the total number of words collected for each company across the various elements of its website as described above.

To investigate how transparency emerges in the IR policies of the Italian and Finn- 
Table 4: Finnish/Italian datasets for rhetorical move analysis

\begin{tabular}{|c|c|c|c|c|c|}
\hline Finnish Companies & Document Label & Word Count & Italian Companies & Document Label & Word Count \\
\hline Amer & $\begin{array}{l}\text { Communications } \\
\text { policy }\end{array}$ & 239 & Autogrill & IR policy & 121 \\
\hline Huhtamäki & $\begin{array}{l}\text { Investor relations } \\
\text { at Huhtamaki }\end{array}$ & 131 & Campari & IR policy & 230 \\
\hline Fortum & IR policy & 202 & Generali & IR policy & 269 \\
\hline Kesko & IR principles & 230 & Luxottica & IR policy & 120 \\
\hline Kone & $\begin{array}{l}\text { Investor relations } \\
\text { policy }\end{array}$ & 133 & Mediobanca & IR policy & 191 \\
\hline Nokian Tyres & $\begin{array}{l}\text { Principles of investor } \\
\text { relations }\end{array}$ & 141 & Mediolanum & IR policy & 248 \\
\hline Orion & IR policy & 125 & Pirelli & IR policy & 163 \\
\hline Tieto & IR and disclosure rule & 420 & Prysmian & IR activity & 441 \\
\hline Valmet & IR principles & 175 & Saipem & IR policy & 161 \\
\hline Wärtsilä & $\begin{array}{l}\text { Investor relations } \\
\text { policy }\end{array}$ & 266 & World Duty Free Group & IR policy & 253 \\
\hline YIT & IR policy & 245 & & & \\
\hline Total & & 2307 & Total & & 2197 \\
\hline
\end{tabular}

ish companies, we used a complementary two-pronged methodological approach: (1) micro-linguistic analysis to extract keywords related to the concept of transparency, and (2) rhetorical move analysis (Swales, 1990) to identify recurring rhetorical patterns, thus reflecting an integration of quantitative and qualitative techniques.

For the micro-linguistic analysis, we relied on methods of corpus linguistics to systematically identify and retrieve linguistic items of interest across both corpora. Such methods have been successfully implemented to offer in-depth insights into other genres that target investors, including the semantic and pragmatic features of financial analysts' reports relating to BNP Paribas and the Bank of China (Cheng \& Ho, 2017), the discourse of climate change in oil companies' CSR reports (Jaworska, 2018), the strategic use of language when communicating good vs. poor performance in letters to shareholders of U.S. commercial banks (Poole, 2016), and the pragmalinguistic expression of persuasion in earnings conference calls (Crawford Camiciottoli, 2018). In the present study, the Italian corpus and the Finnish corpus were processed with the corpus analysis software Wmatrix (Rayson, 2008). Specifically, the software automatically identifies words that occur with statistically higher frequencies (i.e., keywords) in a target corpus by comparing them to a reference corpus incorporated within the software. In this case, we selected the Business subcorpus sampler (134275 words) of the British National Corpus among those incorporated in the software as the most appropriate reference corpus for comparative purposes. Using the log-likelihood statistical test, Wmatrix calculates a keyness score that serves to identify and rank highly distinctive words in the target corpus. Once the keywords were identified across both corpora, those with meanings that could be linked to transparency were then further examined within their context of usage for additional insights.

For the rhetorical move analysis, two smaller datasets were extracted from the Italian and Finnish corpora. These included texts explicitly labelled by companies as relating to a policy or principles of IR communication, as shown in Table 4 . In other words, texts sporadically located across other types of financial documentation were excluded from the analysis, as were the "full-length" disclosure policies. This solution was driven by the need to have some degree of uniformity in order to perform an accurate move analysis.

The rhetorical analysis applied the procedure of corpus-based move analy- 
sis described by Upton and Cohen (2009), based on a manual examination of texts taking co-text and the context into account. A move is here understood as a rhetorical component having a communicative function (see Swales, 1990). A preliminary list of moves was drafted and checked against the corresponding datasets, and constantly refined and redefined. For analytical purposes, a requirement of presence in at least four texts was established for each move. An inter-rater reliability coding procedure was carried out by three independent and trained coders in addition to Author 1: two Master's students and one post-doctoral researcher, leading to a joint agreement of the results presented in Table 7 . The percentage of agreement for the coders ranged between approximately $80 \%$ for the Italian dataset and approximately $75 \%$ for the Finnish dataset. As the coding was not carried out on sentence level, but instead based on the meaning expressed, disagreements concerned different interpretations of the scope and number of steps. These cases were discussed until a consensus on the level of detail was reached by the post-doctoral researcher and Author 1. Table 8 in the Appendix provides examples of the lexical cues utilized to distinguish moves and steps from both the Finnish (FI) and Italian (IT) datasets.

The findings from both the micro-linguistic analysis and the rhetorical move analysis were then broadly interpreted with reference to prevailing notions of cultural alignment, specifically Gudykunst and Ting-Toomey's (1988) model of cultural variability in interpersonal verbal communication styles. ${ }^{2}$

2 This model was broadly inspired by the work of Hofstede (1980) and Hall (1976). We recognize that such cultural models have been criticized as suffering from both overgeneralization and essentialism - see Piller (2009), Sarangi (1994) and Cardon (2008), among others. However, we argue that they are nonetheless useful for exploring potential alignment / disalignment with expected cultural values, which perhaps explains why they continue to be widely applied.

\section{Results and discussion}

In this section, we present and interpret the results of the two-pronged analysis of the concept of transparency across the Italian and Finnish datasets, first from the micro-linguistic perspective based on corpus methods, and then from the rhetorical perspective based on moves analysis. We conclude the section with a discussion of how the unique cultural and historical aspects of each country are reflected in the findings.

\subsection{The micro-linguistic analysis}

Table 5 reports the statistically significant keywords in the Italian corpus whose meanings could be interpreted as relating to the concept of transparency. The table lists the keyword, the number of occurrences in the Italian corpus, the number of occurrences in the reference corpus, and the resulting keyness score calculated by Wmatrix using the log-likelihood test. This measure is based on a comparison between observed frequencies in the target corpus with frequencies that would be expected if the null hypothesis were true, i. e., that there would be no significant difference between frequencies in the target vs. the reference corpus. To be considered statistically more frequent in the target corpus (in this case, the Italian corpus) at the $99 \%$ level of confidence ( $p>0.01)$, words must have a keyness score of at least 6.63.

As can be seen, both transparency and transparent are keywords, although not among those with the highest keyness scores. Examples 1-4 illustrate how these items were used in the Italian corpus.

1. [...] the Group's wish to provide timely, transparent information to support its relations with the financial community. [...] (Yoox)

2. [...] comply with statutory obligations and transparency requirements for the institutional information [...]. (Banca Intesa San Paolo)

3. The objective of our IR policy, inspired by the principles of fairness and transparency, is to ensure the timely disclo- 
Table 5: Transparency-related keywords in the Italian corpus

\begin{tabular}{lccr}
\hline Keyword & Italian Corpus (N) & Reference Corpus (N) & Keyness Score \\
\hline 1. dialogue & 48 & 26 & 291.63 \\
2. timely & 32 & 3 & 237.39 \\
3. community & 64 & 257 & 204.06 \\
4. transparent & 21 & 14 & 122.55 \\
5. transparency & 12 & 1 & 89.65 \\
6. ongoing & 13 & 3 & 89.38 \\
7. promptly & 14 & 6 & 88.55 \\
\hline
\end{tabular}

sure and circulation of true, clear, accurate and complete information [...]. (Campari)

4. [...] communication which is active, transparent, well-timed, constant, correct. (A2A)

In examples 1-3, transparent and transparency appear together with information, reflecting a clear alignment with text found in the Italian Corporate Governance Code (Borsa Italiana, 2015): [...] consistently with the objectives of good corporate governance, transparency of information and protection of investors and the markets pursued by the Code [...]. This suggests that the Italian companies refer closely to normative documents when formulating IR communication policy. In examples 3 and 4 , the keywords are accompanied by other items with meanings that encode aspects of ethical behavior, competence, and diligence (e.g., fairness, true, constant, accurate), which further serve to convey a sense of trustworthiness.

In addition to transparent and transparency, some other items emerged that could be conceptually linked to transparency, including dialogue, timely, community, ongoing, and promptly, which seem to reinforce a concern to maintain transparent relations with the investment community, thus helping to engender trust. The item dialogue was particularly prominent and is inherently related to transparency as the "instrument" through which it is communicated. Examples 5-7 demonstrate how this item was used, indicating strong similarities and even basically reiterating text that appears in the Italian code: The Committee believes that it is in the best interests of the issuers to establish a continuing dialogue with generality of the shareholders, and in particular, with institutional investors [...]. These results suggest that little effort is made to expand on prescribed language forms and to produce communications that sound less "canned".

5. [...] establishing a continuous dialogue with the institutional investors and the shareholders. (Buzzi Unichem)

6. [...] to establish an ongoing dialogue with its shareholders in general, as well as with institutional investors. (Enel)

7. [...] to maintain constant dialogue with its Shareholders, potential investors and financial analysts [...]. (Ferragamo)

Interestingly, there was only one instance in which transparent and dialogue were combined, (example 8), although there were two that combine transparent and open, as shown in example 9, where open can be interpreted as synonymous to transparent in this context. Thus, there appears to be scarce attention to communicating the inherent connection between transparency and dialogue on a conceptual level.

8. In order to have an open, immediate and transparent dialogue with all those in need of financial information on Pirelli, the Pirelli website has a section called "Investors" [...]. (Pirelli)

9. [...] to ensure an open dialogue between the Group's Top Management and its actual and potential Shareholders. (Autogrill)

Table 6 lists the seven relevant keywords that emerged from the Finnish corpus, 
Table 6: Transparency-related keywords in the Finnish corpus

\begin{tabular}{lccr}
\hline Keyword & Finnish Corpus (N) & Reference Corpus (N) & Keyness Score \\
\hline 1. material & 79 & 8 & 248.86 \\
2. principles & 48 & 2 & 165.94 \\
3. publication & 46 & 2 & 158.52 \\
4. publishes & 40 & 0 & 151.74 \\
5. rumors & 27 & 0 & 102.42 \\
6. public & 46 & 21 & 98.00 \\
7. simultaneously & 25 & 0 & 94.84 \\
\hline
\end{tabular}

showing the item, the number occurrences in the Finnish corpus, the number of occurrences in the reference corpus, and the keyness score. Particularly notable was the fact that none of the seven transparency-related keywords found in the Italian corpus emerged as key in the Finnish corpus. The main item that could be most clearly traced back to the concept of transparency was the second-ranking item principles, an item that instead did not emerge as key in the Italian corpus.

Examples 10-13 illustrate the item principles in context of usage. The primary emphasis on principles rather than transparency seems to suggest a particular concern for regulatory compliance. Examples 10 and 11 highlight the descriptive perspective, while example 12 and 13 also address the notion of transparency / openness, but in a less prominent way by simply listing it along with other desirable features.

10. This policy describes the main principles on how Outokumpu communicates with the capital markets and discloses share price sensitive information to its stakeholders. (Outokum$\mathrm{pu})$

11. This Elisa Disclosure Policy describes the key principles which Elisa follows when communicating to the capital market. (Elisa)

12. The key principles in Orion's communications are openness, impartiality, reliability, simultaneousness and consistency. (Orion)

13. The key principles in YIT's communications are consistency, equitability, transparency, honesty and proactiveness. (YIT)

While the Italian corpus reiterates the wordings of the Italian Corporate Governance Code, the Finnish corpus in a similar manner echoes the recommendations by the Financial Supervisory authorities (FIN-FSA, 2014) stating that [...] issuers should define their operating principles and procedures for communication with the capital markets. This recommendation is carried out exactly in examples 12 and 13. However, the principles that are listed seem to be company-specific to the degree that none of them appear as keywords (see also Koskela, 2018).

In addition to principles, a conceptual link to transparency (albeit perhaps less obvious) can be recognized in some other words the emerged as key in the Finnish corpus: public, publishes, publication, material, and simultaneously. In connection with information, these can also be intertextually traced back to norms and recommendations (FIN-FSA, 2017) requiring that $[. .$.$] all investors have equal, equitable$ and simultaneous access to information and that [...] an issuer is obliged to keep such information available to investors in an equal and consistent manner, which is likely to have a material effect on the price of a security. The highest keyness score of material is in part explained by polysemy as it may refer either to the general noun describing any type of publication or to the term material information having intertextual ties to legislative texts. In fact, the Finnish authorities (FIN-FSA, 2010) suggest that companies in their disclosure policies should define what they under- 
stand as material information, i.e., information that may affect the value of stock). A particularly interesting keyword in the Finnish data is rumors because it reminds readers of the downside of transparency, as companies apparently feel the need to declare that their principle is not to comment on rumors.

\subsection{The rhetorical analysis}

The rhetorical purpose of the IR policy is to convince the public of the transparency of the company by explicating the principles the company follows in its financial communication. However, there may be different interpretations of which public should be considered primary, as both internal and external publics seem to be addressed (Koskela \& Kuronen, 2014). Guimard (2008) emphasizes the role of disclosure policies as internal guidance for employees working on financial communication. In this sense, IR policies seem to perform the same task, which beg the question of what the difference between a disclosure policy and an IR policy actually is, if any. The distinction between organizational and communicative transparency (Rawlins, 2009), as introduced in section 2 , might be one explanation for why two types of policies are sometimes used by the Finnish companies. Accordingly, disclosure policies mainly serving as internal guidance for employees would represent organizational transparency, while IR policies would be mainly targeting publics outside the companies, including relevant authorities, and thus serve the purposes of communicative transparency. In the Italian context, IR policies only seem to be public, which may indicate that they are directed primarily towards external stakeholders.

In order to gain insight into how transparency is conceptualized in the IR policies of Finnish and Italian listed companies, we applied move analysis (see Swales, 1990; Bhatia, 1993). We see moves as semantic and functional patterns with specific communicative purposes, which contribute to conceptualizing transparency in a certain way. Even though move analysis has been traditionally used to identify recurring structural and linguistic patterns of genres in order to teach them to novices, we use it as a method to make visible the potential differences in rhetorical choices between the two corpora. A move-step structure of fers a variety of rhetorical choices that may be applied to realize a certain move (Bhatia, 1993, pp. 30-31). Therefore, we see the moves and the steps as rhetorical options which companies use to serve the goal of transparency creation in the best possible way. In other words, companies choose from a variety of rhetorical options to dis-

Table 7: The overall move structure of Italian and Finnish IR policies

\begin{tabular}{lll}
\hline Move 1 & Introductory text on company IR \\
& Step 1 & Stating general objectives, aims and tasks \\
& Step 2 & Explaining communication principles followed \\
\hline Move 2 & Company practices & \\
& Step 1 & Describing rules and requirements adapted in company IR \\
& Step 2 & Describing channels and means of communication \\
& Step 3 & Describing financial information, reports and other releases \\
& Step 4 & Informing about silent period \\
& Step 5 & Describing co-operation with stakeholders and other professionals \\
\hline Move 3 & IR relations & \\
& Step 1 & Encouraging stakeholders to be active partners \\
& Step 2 & Expressing the interest to co-operate with stakeholders \\
\hline Move 4 & Responsibilities and contacts \\
& Step 1 & Identifying people and quarters responsible for IR \\
& Step 2 & Informing of the silent period \\
& Step 3 & Providing contact information \\
\hline
\end{tabular}


play a transparent image of themselves. After identifying the typical moves and steps, from the perspective of genre analysis the goal is to explain why the specific features were chosen by the companies to achieve their communicative purpose (Bhatia, 1993).

We will return to this question in the final section of our paper. Table 7 summarizes the rhetorical moves typical of the genre of IR policy. The categorization covers both Italian and Finnish data, which means that not only steps but also some moves are voluntary.

The overall move structure of all IR policies in the data consists of four moves through which companies seek to convince the public of their status as transparent actors. Rhetorically, this is carried out by characterizing the company policy (Move 1) and describing company practices at differing levels of detail (Move 2). The two first moves are obligatory, while Move 3 seems to be voluntary in the Finnish context and Move 4 may be absent if the policy is short. Next we will look more closely first at the Italian dataset and then at the Finnish dataset.

The Italian dataset. The rhetorical analysis of the Italian dataset revealed that Move 1 with both steps seems to be obligatory as it is present in all Italian policies. Move 2 is only missing in two policies, but moves 3 and 4 are found in about half of the policies.

The move analysis shows that Italian IR policies follow a rather standardized rhetorical pattern. The texts tend to be descriptive including, for example, details about communication channels and means of communication. In line with the results of the micro-linguistic analysis, a distinctive structural element in the Italian data is included in Move 3: encouraging stakeholders to be active partners and emphasizing the interest to co-operate with the stakeholders, that is, highlighting the importance of dialogue. These statements are rhetorically interesting because they tend to represent the company as superordinate to investors, i.e., able to influence them.
Examples 14-16 further illustrate the character of the moves in the Italian dataset. Example 14 shows how Italian companies tend to use elaborate promotional language (key priority, highest standards) and also explicitly mention transparency in Move 1, when describing objectives and principles of financial communication. Example 15 makes reference to means of communicating (Move 2), simultaneously stating a more abstract goal: communication shall be coherent and ongoing. This goal is shared by Italian companies to the degree that it has the sixth highest keyness score. The concrete means of communicating can be listed, but are often referred to in rather general terms such as various ways (example 15), typical tools or all main instruments of communicating. Example 16 illustrates Move 3, maintaining good relations with stakeholders: Pirelli refers to maintaining a dialogue through transparent, timely, fair and accurate communications.

14. Creating value for shareholders, and other stakeholders, is a key priority for Prysmian, whose policy of strategic and financial communication is directed towards the highest standards of accuracy, clarity and transparency. (Prysmian)

15. The financial community is kept informed of company developments in various ways, in line with a framework of coherent and ongoing communication that relies also on a constantly updated and bilingual website. (Campari)

16. Pirelli maintains a constant dialogue with analysts and investors (both institutional and individual) through its Top Management and Investor Relations division, promoting transparent, timely, fair and accurate communications, to enable correct assessment of the Group and its assets. (Pirelli)

The Finnish dataset. In the Finnish dataset, Move 1 seems to be obligatory, Moves 2 and 4 again seem to be optional and Move 3 is rare. Interestingly, the Finnish texts have more variation concerning the optional steps than the Italian texts. This indicates 
that IR policy may serve different company-specific communicative purposes, depending on the organizational context and the genre system of the company as a whole.

A distinctive feature, also highlighted in the micro-linguistic analysis, is mentioning the rules and requirements adapted in company IR (Move 2, Step 1). IR is thus rhetorically presented as a rule-governed activity, which also leads to the impression that communication is predominantly seen as one-way information transfer from the company to the stakeholders, and only to a minor degree in the opposite direction. Unlike in the Italian data, descriptions of channels and means of communication tend to be precise and concrete (Move 2, Step 2), making the descriptions strong arguments for transparency in practice.

Move 3, referring to the cooperation with stakeholders and other professionals is not highlighted as it is in the Italian data, but occurs as optional in some of the policy texts. A commonly occurring step in the Finnish policy texts, not used in the Italian data, is the mention of the silent period (Move 2, Step 4), that is, the time before reporting financial results when the company does not communicate with the stakeholders. From the point of view of transparency, this period forms a clear limitation, thus meriting mention.

17. The key IR principles are to provide reliable, comprehensive, timely and comparable information regularly and to ensure that all market participants have a possibility for equal, equitable and simultaneous access to the information. (Huhtamäki)

18. In all of its communications, KONE complies with the requirements for listed companies as defined by the Securities Markets Act, the rules of the NASDAQ OMX Helsinki Ltd and any other applicable regulation concerning prompt and simultaneous disclosure of information. (Kone)

19. Tieto follows 21 days quiet period_before the time of the publication of an interim report and financial statement bulletin and ending one hour thereafter. (Tieto)

Example 17 (Move 1, Step 2) illustrates how the central principles of financial communication mentioned in most recommendations are highlighted with an unusually extensive listing with a hint of promotional tone. However, even though a similar structure echoing authoritative recommendations and guidelines is used repeatedly, the number and choice of adjectives and adverbs tend to vary according to the company (see Koskela, 2018, p. 21). The rule-orientation of the Finnish IR practice becomes evident in example 18 (Move 2, Step 1), with a formulation (i.e., complies with the requirements) that is repeated in almost identical form by four companies. Example 19 again (Move 2, Step 4) shows a similar formulaic expression concerning the quiet period. Overall, the repetition of formulaic expressions serves a rhetorical purpose in the sense that it makes the Finnish text rather strict and formal with little room for promotional tone. Simultaneously, it tends to focus on the role of the company as information provider, not on the relationship with stakeholders.

\subsection{Cultural and historical considerations}

According to Melgin et al. (2018, p. 418), "[d]espite being embedded in global trends, investor relations' action and communication reflect its surrounding cultural environment". Our results similarly reflect the influence of cultural conditions on how IR policy is shaped, as both the micro-linguistic and rhetorical move analyses indicate some convergence with stereotypical cultural alignments associated with Italy and Finland. For example, with reference to contextual vs. personal orientations (Gudykunst \& Ting-Toomey, 1988), contextual orientation is seen in the Italian companies' focus on their social role in relation to the stakeholders, which emerges in the prominent use of words such as $d i$ alogue, community, and ongoing. This emphasis on relational aspects in the Italian data is aptly reflected in Comin, Ros and Scotti (2017, p. 443) characterization of 
Italian companies: “A company's life [...] is linked to its ability to create and maintain relationships." In contrast, the personal orientation emerges when the Finnish authors orient towards their own company as the companies predominantly seem to understand communication as one-way information-giving, where the company itself is the actor (as indicated by the keywords publish, release, information). In terms of instrumental vs. affective orientations, there seems to be an instrumental orientation in the Finnish companies' IR communication seen in their sender (the company) and information-oriented communications. An affective orientation instead emerges in the receiver and process-oriented communication of the Italian companies that emphasize dialogue as an ongoing endeavour. Finally, Gudykunst and Ting-Toomey's (1988, p. 105) distinction between elaborate and exacting verbal communication styles is reflected, respectively, in the richly promotional tone of the Italian companies vs. the concise and to-the-point language of the Finnish companies.

In addition to cultural influences, it is also important to consider how the historical development of transparency practices may contribute to shaping IR policy. The Finnish IR policies are a recent development based on disclosure policies, which has been an established genre since 2008 (Koskela \& Kuronen, 2014), and the intertextual relation between these two document types may be one explanation for the organization-centred character of the Finnish documents, which highlights organizational transparency. The Italian IR policies instead appear to be a new or emerging textual form, which is more freely adapted to the needs of relationship management between stakeholders and the companies, thus emphasizing communicative transparency.

An important feature of the IR policies used in both countries relates to how they are intertextually embedded within the genre system of financial communication in terms of both national regulatory frames and company-specific solutions. The intertextual character of the documents thus shapes their linguistic and rhetorical / structural choices. Moreover, the intertextual features also reflect the historical development of the norms and recommendations in both countries (for changes in Finnish norms, see Koskela, 2018). In the Italian context, the Corporate Governance Code seems to be a major source of intertextuality, while in the Finnish context, the role is taken by recommendations from the authorities and rules of the stock exchange. This difference is an example of how global (and shared European) trends are translated into local practices within the limitations induced by cultural, historical, and legislative frames in each country.

\section{Concluding remarks}

In this paper, we integrated quantitative and qualitative methods to analyze the linguistic and discursive features of the IR communication practices of Finnish and Italian listed companies, with particular reference to how transparency is conceptualized, as well as what potential influence national cultures may have on the understanding of what constitutes transparency and how that may lead to trust. Overall, the presence of IR policy-related textual material demonstrates that both Italian and Finnish listed companies share a concern to provide honest, comprehensive, and coherent information to the markets, which is at the core of the idea of transparency promoted by the EU and national bodies issuing recommendations. To return to research questions posed at the outset of this paper, the linguistic analysis revealed a range of more or less explicit lexical choices used to encode meanings relating to transparency in both corpora. The move analysis showed that both datasets have their distinct move structures with one obligatory and 2 or 3 optional moves with many shared features. However, the lack of overlap in transparency-related lexical choices between the two corpora indicates a substantially different conceptualization of transparency. On a discursive level, the Italian texts tend to be descriptive and at times promotional, 
while the Finnish are more matter of fact and oriented to efficient communication. This variation also points to a different idea of the communication process. While the Italian companies emphasize the relational aspect of constant dialogue with the stakeholders, the Finnish companies focus on the norm-based organization-centred idea of information-giving, which may lead to the impression that transparency practices are answers to the requirements by authorities rather than voluntary measures taken to involve stakeholders. The two approaches to communicating transparency also show alignments with prevailing theories of cultural differences; the Italian corpus has a contextual and affective orientation, while the Finnish corpus has a personal and instrumental orientation (Gudykunst \& Ting-Toomey, 1988).

The type of cross-national comparisons undertaken in this study may open new avenues for an analysis of how the changing global environment and diverse cultural settings are reflected in the linguistic and rhetorical features of IR policy communications. Our study has focused only on one northern European country and one Southern European one. Additional insights could be gained by extending the analysis to include not only other European countries, but also to extra-European countries, such as those in North and South America and in Asia, where cultural factors may play an even greater role. An expansion of this nature would also be helpful to understand to what extent the IR policy as described in this study may be considered a genre (or perhaps an emerging genre) on the corporate world scene.

\section{Acknowledgements}

We are very grateful to Marja-Liisa Kuronen, Mona Enell-Nilsson and the student coders of the data for their valuable contribution to this research.

\section{References}

Albu, O. B., \&Wehmeier, S. (2014). Organizational transparency and sense-making: The case of Northern Rock. Journal of Public Relations Research, 26(2), 117-133.

Amernic, J., Craig, R., \& Tourish, D. (2010). Measuring and assessing tone at the top using annual report CEO letters. Edinburgh: The Institute of Chartered Accountants of Scotland.

Argenti, P. (2009). Corporate Communication. New York: McGraw-Hill.

Baraibar-Diez, E., Odriozola, M.D., \& Fernández Sánchez, J.E. (2016). Transparency through European corporate governance codes. International Journal of Disclosure and Governance, 13(3), 244-261.

Bhatia, V. K. (1993). Analysing genre: Language use in professional settings. London: Longman.

Borsa Italiana. (2002). Guide to the disclosure of information to the market. Retrieved from https://www.refricerche.it/it/ downloads $/$ ? search $=$ guide $\&$ ambito $=\&$ pageID $=4$.

Borsa Italiana. (2015). Codice di Autodisciplina (Italian Corporate Governance). Retrieved from http://www.borsaitaliana. it/comitato-corporate-governance/ codice/2015engclean.en.pdf.

Bruce, I. (2014). Enacting criticality in corporate disclosure communication: The genre of the fund manager commentary. International Journal of Business Communication, 51(4), 315-336.

Cardon, P.W. (2008). A critique of Hall's contexting model: A meta-analysis of literature on intercultural business and technical communication. Journal of Business and Technical Communication, 22, 399-428.

Cheng, W., \& Ho, J. (2017). A corpus study of bank financial analyst reports: Semantic fields and metaphors. International Journal of Business Communication, 54(3), 258-282.

Christensen, L.T., \& Cheney, G. (2015). Peering into transparency: Challenging ideals, proxies, and organizational practices. Communication Theory, 25(1), 70-90.

Crawford Camiciottoli, B. (2018). Persuasion in earnings calls: A diachronic pragmalin- 
guistic analysis. International Journal of Business Communication, 55(3), 275-292.

Comin, G., Ros, S. \& Scotti, A. (2017). The evolution of financial communication in Italy. In A.V. Laskin (Ed.), The handbook of financial communication and investor relations (pp. 443-448). Chichester, UK: John Wiley \& Sons, Ltd.

Directive 2004/109/EC. Retrieved from https://tinyurl.com/Directive-2004.

Directive 2013/50/EU. Retrieved from https://tinyurl.com/Directive-2013.

FIN-FSA (2010). Fivan esitykset IR- ja talousväelle. Retrieved from https://tinyurl.com/ FIN-FSA-2010.

FIN-FSA (2014). Market newsletter 3/2014. Retrieved from https://tinyurl.com/ FIN-FSA-2014.

FIN-FSA (2017). Disclosure obligation. Retrieved from https://tinyurl.com/ FIN-FSA-2017.

Gudykunst, W.B. \& Ting-Toomey, S. (1988). Culture and interpersonal communication. Newbury Park, CA: Sage.

Guimard, A. (2008). Investor relations: Principles and international best practices of financial communications. London, England: Palgrave Macmillan.

Hall, E.T. (1976). Beyond culture. New York, NY: Doubleday.

Hansen, H. K., Christensen, L.T. \& Flyverbom, M. (2015). Introduction: Logics of transparency in late modernity: Paradoxes, mediation and governance. European Journal of Social Theory, 18(2), 117-131.

Hoffman, C., \& Fieseler, C. (2012). Investor relations beyond financials: Non-financial factors and capital market image building. Corporate Communications: An International Journal, 17(2), 138-155.

Hofstede, G. (1980). Culture's consequences: Comparing values, behaviors, institutions and organizations across nations. Beverly Hills, CA: Sage.

Jaworska, S. (2018). Change but no climate change: Discourses of climate change in corporate social responsibility reporting in the oil industry. International Journal of Business Communication, 55(2), 194-219.

Koskela, M., \& Kuronen, M. L. (2014). The essence of a hybrid genre: The causes of variation in corporate disclosure policies. In G. Budin \& V. Lušicky (Eds.), Languag- es for special purposes in a multilingual transcultural world. Proceedings of the $19^{\text {th }}$ European symposium on languages for special purposes, 8-10 July 2013. Vienna, Austria. Retrieved from https://lsp2013. univie.ac.at/proceedings.

Koskela, M. (2018). Disclosing principles of IR communication: Rhetorical moves for constructing transparency. International Journal of Business Communication, 55(2), 164-193.

Laskin, A.V. (2018). Investor relations and financial communication: the evolution of the profession. In A.V. Laskin (Ed.), The handbook of financial communication and investor relations (pp. 2-22). Chichester, UK: John Wiley \& Sons, Ltd.

Laskin, A.V. (2018). The narrative strategies of winners and losers: Analyzing annual reports of publicly traded corporations. International Journal of Business Communication, 55(3), 338-356.

Lee, T.H., \& Boynton, L.A. (2017). Conceptualizing transparency: Propositions for the integration of situational factors and stakeholders' perspectives. Public Relations Inquiry, 6(3), 233-251.

Marston, C.L. (1996). The organization of the investor relations function by large UK quoted companies. Omega, 24(4), 477-488.

Melgin, E., Luoma-aho, V., Hara, M., \& Melgin, J. (2018). The Nordic approach to investor relations. In A.V. Laskin (Ed.), The handbook of financial communication and investor relations (pp. 419-428). Chichester, UK: John Wiley \& Sons, Ltd.

Nasdaq Nordic (2019). Rules of the exchange. Retrieved from https://tinyurl.com/ Nasdaq-Nordic-2019.

National Investor Relations Institute (NIRI). (2018). About NIRI. Retrieved from https:// www.niri.org/about-niri.

Palmieri, R. (2018). The role of argumentation in financial communication and investor relations. In A.V. Laskin (Ed.), The handbook of financial communication and investor relations (pp. 45-60). Chichester, UK: John Wiley \& Sons, Ltd.

Piller, I. (2009). Intercultural communication. In F. Bargiela-Chiappini (Ed.), The Handbook of Business Discourse (pp. 317-329) Edinburgh: Edinburgh University Press. 
Poole, R. (2016). Good times, bad times: A keyword analysis of letters to shareholders of two Fortune 500 banking institutions. International Journal of Business Communication, 53(1), 55-73.

Rawlins, B. (2009). Give the emperor a mirror: Toward developing a stakeholder measurement of organizational transparency. Journal of Public Relations Research, 21(1), 71-99.

Rayson, P. (2008). From keywords to key semantic domains. International Journal of Corpus Linguistics, 13(4), 519-549.

Rousseau, D. M., Sitkin, S. B., Burt, R. S., \& Camerer, C. (1998). Not so different after all: A cross-disciplinary view of trust. Introduction to special topic forum. Academy of Management Review, 23(3), 39-404.

Sarangi, S. (1994). Intercultural or not? Beyond celebration of cultural differences in miscommunication analysis. Pragmatics, 4(3), 409-427.
Strauss, N. (2018). The role of trust in investor relations: A conceptual framework. Corporate Communications: An International Journal, 23(1), 2-16.

Swales, J. M. (1990). Genre analysis: English in academic and research settings. Cambridge: Cambridge University Press.

Upton, T.A., \& Cohen, M.A. (2009). An approach to corpus-based discourse analysis: The move analysis as example. Discourse Studies, 11(5), 585-605.

Volk, S.C. (2017). Towards comparative research in strategic communication: A systematic analysis of cross-national studies and future directions. International Journal of Strategic Communication, 11(5), 434-453.

Xerox. (2008). Xerox corporation disclosure policy and guidelines. Retrieved from https://www.news.xerox.com/investors/ disclosure. 


\section{Appendix}

\section{Table 8: Lexical cues to the move structure}

\begin{tabular}{|c|c|c|c|}
\hline Moves & Categories of steps & & Lexical cues \\
\hline \multirow[t]{3}{*}{ Move 1} & \multicolumn{3}{|c|}{ Introductory text on company IR } \\
\hline & Step 1 & $\begin{array}{l}\text { Stating general objectives, } \\
\text { aims and tasks }\end{array}$ & $\begin{array}{l}\text { "... the goal / aim / purpose of investor relations is ..." (FI) } \\
\text { "... is committed/ contributes to ... objective, aim, task" (IT) }\end{array}$ \\
\hline & Step 2 & $\begin{array}{l}\text { Explaining communication } \\
\text { principles followed }\end{array}$ & $\begin{array}{l}\text { Adjectives, adverbs } \\
\text { "... follows the principle(s) of ... -ness; - -ity, -cy" (FI) } \\
\text { "regularly ... information ... prompt, accurate, effective" (IT) }\end{array}$ \\
\hline \multirow[t]{6}{*}{ Move 2} & \multicolumn{3}{|l|}{ Company practices } \\
\hline & Step 1 & $\begin{array}{l}\text { Describing rules and require- } \\
\text { ments adapted in company IR }\end{array}$ & $\begin{array}{l}\text { "... applies/complies with the requirements ... rules ... } \\
\text { laws ... legislation Securities Markets Act ..." (FI) }\end{array}$ \\
\hline & Step 2 & $\begin{array}{l}\text { Describing channels and means } \\
\text { of communication }\end{array}$ & $\begin{array}{l}\text { "phone or e-mail, or meetings, Capital Markets Day, } \\
\text { conferences, conference calls, road show events, } \\
\text { participation in investor conferences" (FI) } \\
\text { "various / variety of channels; direct contact, one-to-one- } \\
\text { meetings, websites, webcasts, conference calls, conferences, } \\
\text { attend road shows, targeted initiatives" (IT)" }\end{array}$ \\
\hline & Step 3 & $\begin{array}{l}\text { Describing financial information, } \\
\text { reports and other releases }\end{array}$ & $\begin{array}{l}\text { "financial information ... disclosure ... reports ... available } \\
\text { releases ... publishes ... reports" (FI) "press releases, annual } \\
\text { reports and other relevant information" (IT) }\end{array}$ \\
\hline & Step 4 & Informing about silent period & "... observes ... applies ... silent ... period" (FI) \\
\hline & Step 5 & $\begin{array}{l}\text { Describing co-operation } \\
\text { with stakeholders and other } \\
\text { professionals }\end{array}$ & $\begin{array}{l}\text { "... discussions with ... answer ... meet ... analysts ... } \\
\text { investors, gathering and analyzing market information } \\
\text { and investor feedback to be used by management" (FI) } \\
\text { "constant dialogue; top management meets ... } \\
\text { financial community" (IT) }\end{array}$ \\
\hline \multirow[t]{3}{*}{ Move 3} & \multicolumn{3}{|l|}{ IR relations } \\
\hline & Step 1 & $\begin{array}{l}\text { Encouraging stakeholders } \\
\text { to be active partners }\end{array}$ & "encourage shareholders, investors, stimulate interest" (IT) \\
\hline & Step 2 & $\begin{array}{l}\text { Expressing the interest to } \\
\text { co-operate with stakeholders }\end{array}$ & $\begin{array}{l}\text { "discuss, two-way dialogue, maintain good relations, } \\
\text { pay attention" (IT) }\end{array}$ \\
\hline \multirow[t]{3}{*}{ Move 4} & \multicolumn{3}{|c|}{ Responsibilities and contacts } \\
\hline & Step 1 & $\begin{array}{l}\text { Identifying people and quarters } \\
\text { responsible for IR }\end{array}$ & $\begin{array}{l}\text { "responsible ... CFO ... CEO ... IRO" (FI) "handled by relevant } \\
\text { units; names of persons; responsibility CFO, Department" (IT) }\end{array}$ \\
\hline & Step 3 & Providing contact information & $\begin{array}{l}\text { "contact information" (FI), "telephone numbers, } \\
\text { email addresses, website" (IT) }\end{array}$ \\
\hline
\end{tabular}

